\title{
GABA Regulates Excitatory Synapse Formation in the Neocortex via NMDA Receptor Activation
}

\author{
Doris D. Wang and Arnold R. Kriegstein \\ Institute for Regeneration Medicine, University of California, San Francisco, San Francisco, California 94143
}

The development of a balance between excitatory and inhibitory synapses is a critical process in the generation and maturation of functional circuits. Accumulating evidence suggests that neuronal activity plays an important role in achieving such a balance in the developing cortex, but the mechanism that regulates this process is unknown. During development, GABA, the primary inhibitory neurotransmitter in adults, excites neurons as a result of high expression of the $\mathrm{Na}^{+}-\mathrm{K}^{+}-2 \mathrm{Cl}^{-}$cotransporter (NKCC1). Using NKCC1 RNA interference knockdown in vivo, we show that GABA-induced depolarization is necessary for proper excitatory synapse formation and dendritic development of newborn cortical neurons. Blocking NKCC1 with the diuretic bumetanide during development leads to similar persistent changes in cortical circuitry in the adult. Interestingly, expression of a voltage-independent NMDA receptor rescues the failure of NKCC1 knockdown neurons to develop excitatory AMPA transmission, indicating that GABA depolarization cooperates with NMDA receptor activation to regulate excitatory synapse formation. Our study identifies an essential role for GABA in the synaptic integration of newborn cortical neurons and suggests an activity-dependent mechanism for achieving the balance between excitation and inhibition in the developing cortex.

Key words: GABA; $\mathrm{GABA}_{\mathrm{A}}$ receptor; AMPA receptor; NMDA receptor; synapse development; synaptogenesis; cortical circuit; activitydependent synaptogenesis

\section{Introduction}

The development of cortical circuitry is a dynamic and complex process whereby newborn neurons must generate precise connections with surrounding neurons to maintain the balance between excitation and inhibition. Of particular interest is the role of neurotransmitters in the regulation of activity-dependent mechanisms of synaptogenesis. During corticogenesis, the principal adult inhibitory neurotransmitter GABA influences the processes of cell proliferation, migration, and differentiation (Barbin et al., 1993; LoTurco et al., 1995; Heck et al., 2007). GABAergic signaling precedes glutamatergic signaling in the developing neocortex because newborn neurons express $\mathrm{GABA}_{\mathrm{A}}$ receptors $\left(G_{A B A} R s\right)$ and receive $G A B A$ ergic inputs from striatally derived interneurons before forming glutamatergic synapses with each other (Owens et al., 1999; Hennou et al., 2002). GABAergic signaling is an ideal regulator of activity-dependent neural circuitry formation for two reasons. First, GABA gates a chloride channel and can either depolarize or hyperpolarize a cell depending on the developmentally regulated expression of $\mathrm{Cl}^{-}$ transporters (Delpire, 2000; Owens and Kriegstein, 2002). Sec-

Received Dec. 18, 2007; revised March 24, 2008; accepted April 17, 2008.

This work was supported by grants from the National Institutes of Health (A.R.K.), the Medical Scientist Training Program (D.D.W.), and the American Epilepsy Society (D.D.W.). We thank members of the Kriegstein laboratory for discussion and manuscript editing, H. Song for providing Nkcc1 cDNA and shRNA constructs, L. Wollmuth for providing NMDA receptor NR2A and NR2A mutant constructs, E. Hueske for providing NMDA NR1 shRNA constructs, and W. Walantus and J. Agudelo for technical support.

Correspondence should be addressed to Doris D. Wang, University of California, San Francisco, 513 Parnassus Avenue, HSW 1201, Box 0525, San Francisco, CA 94143. E-mail: Doris.wang@ucsf.edu.

DOI:10.1523/JNEUROSCI.5599-07.2008

Copyright $\odot 2008$ Society for Neuroscience $\quad$ 0270-6474/08/285547-12\$15.00/0 ond, GABA can excite neurons without directly producing excitotoxicity because the relatively negative GABA reversal potential and large $\mathrm{Cl}^{-}$conductance clamps the membrane potential to prevent long activation of voltage-gated channels that might engender toxic amounts of $\mathrm{Ca}^{2+}$ influx. Using strategies to alter the $\mathrm{Cl}^{-}$gradient in immature neurons, recent studies suggest that GABA-mediated depolarization regulates the synaptic integration of adult-generated hippocampal granule cells as well as formation of glutamatergic synapses in cortical neurons in vitro and in Xenopus tectal neurons in vivo (Chudotvorova et al., 2005; Akerman and Cline, 2006; Ge et al., 2006). The mechanism of the influence of GABA on excitatory synapse development is unknown, and whether the same process applies to developing cortical neurons remains to be answered.

To investigate the role of GABA in synapse development in the neocortex, we aimed to abolish GABA-mediated excitation in cortical excitatory neurons before and during synapse formation. The effect of GABA on membrane polarity depends on the $\mathrm{Cl}^{-}$ gradient created by the expression of $\mathrm{Na}^{+}-\mathrm{K}^{+}-2 \mathrm{Cl}^{-}$cotransporter (NKCC) and $\mathrm{K}^{+}-\mathrm{Cl}^{-}$cotransporter (KCC). NKCC1 imports $\mathrm{Cl}^{-}$and is expressed from the embryonic stage until the first postnatal week, whereas KCC2 exports $\mathrm{Cl}^{-}$and is weakly expressed at birth and upregulated as the brain matures (Plotkin et al., 1997; Rivera et al., 1999; Li et al., 2002). The temporal expression patterns of these two transporters correspond to the switch of GABA from being excitatory to inhibitory during the first few weeks of rodent postnatal life (Delpire, 2000). Here, using in utero electroporation of a short hairpin RNA (shRNA) sequence against $N k c c 1$, we describe a critical role for GABAinduced excitation in the development of excitatory cortical syn- 
apses. Blocking NKCC1 with bumetanide during a critical period in development also leads to a failure to develop excitatory synapses that persists to maturity. Furthermore, we provide evidence that GABA-mediated depolarization through $\mathrm{GABA}_{\mathrm{A}} \mathrm{R}$ activation can cooperate with NMDA receptors to allow the newly formed network to achieve a balance between excitation and inhibition. We thus demonstrate that an inhibitory neurotransmitter in the adult can regulate the development of excitatory synapses at early stages of cortical circuit formation.

\section{Materials and Methods}

Animals. Timed-pregnant Swiss-Webster dams were obtained from Simonsen Laboratories. All manipulations were performed in accordance with the guidelines of the University of California San Francisco Institutional Animal Care and Use Committee.

Construction, in utero injection, and electroporation of shRNAexpressing plasmids. Green fluorescent protein (GFP) and shRNA oligonucleotides were inserted into pLLox3.7 for coexpression under the U6 promoter (Lois et al., 2002). The following previously characterized target sequences were used: ACACACTTGTCCTGGGATT (Nkcc1shRNA); AGTTCCAGTACGGCTCCAA (DsRed-shRNA) (Ge et al., 2006). For NR1 knockdown experiments, shRNA plasmids were provided by E. Hueske (Massachusetts Institute of Technology, Cambridge, MA). The small interfering RNA sequence was screened through GGCAGUAAACCAGGCCAAUTT (Ambion) and cloned into Topo2.1 vector for expression under the U6 promoter. Plasmids were introduced into the in vivo developing cortex by intraventricular injection and electroporation (Saito and Nakatsuji, 2001). Intraventricular injections were performed in embryonic day 15 (E15) timed-pregnant Swiss-Webster mice as described previously (Noctor et al., 2001). Electroporations were performed using an Electro Square Porator ECM830 (Genetronics; five pulses, $45 \mathrm{mV}, 100 \mathrm{~ms}, 1 \mathrm{~s}$ interval). One microliter of DNA was injected per brain at the following concentrations: shRNA constructs at $1.5 \mu \mathrm{g} / \mu \mathrm{l}$; rescue constructs at molar ratios of 2:1 (Nkcc1:Nkcc1-shRNA), 2:1 (YFP: Nkcc1-shRNA), 1:2 (YFP:NR2Amut), 1:2 (YFP:NR2A), and 1:1 (NR2Amut:Nkcc1-shRNA).

Immunohistochemistry and confocal imaging. Coronal brain sections (14 $\mu \mathrm{m}$ thick) were prepared from electroporated brains of neonatal mice after transcardial perfusion with PBS followed by $4 \%$ paraformaldehyde. For NKCC1 staining, the sections were pretreated with $1 \%$ SDS and $8 \% \beta$-mercaptoethanol in PBS for $15 \mathrm{~min}$ as described previously (Ge et al., 2006). Sections were blocked in a solution containing 2\% gelatin, $10 \%$ serum, and $1 \%$ Triton X-100 in PBS for $2 \mathrm{~h}$. Sections were incubated overnight in the following primary antibodies: mouse antiNKCC1 (T4, 1:200; Developmental Studies Hybridoma Bank), rabbit anti-KCC2 (1:400; Upstate Biotechnology), and chicken anti-GFP (1: 500; Aves Labs). Secondary antibodies included Alexa 488/568 conjugates (Invitrogen) or Cy3/Cy5 conjugates (Jackson ImmunoResearch). Images were acquired on an Olympus Fluoview 300 and a Leica SP5 laser-scanning confocal microscope. Images of NKCC1 staining represent collapsed $3 \mu \mathrm{m}$ stacks collected at $1 \mu \mathrm{m}$ steps. Images were analyzed using Photoshop 7.0 (Adobe Systems).

Cell iontophoresis and morphological analysis. Electroporated postnatal mice were perfused as described previously, and $300-\mu \mathrm{m}$-thick coronal sections were cut using a Vibratome (Leica VT1000S) and stored in PBS. $\mathrm{GFP}^{+}$pyramidal neurons were visualized by differential interference contrast (DIC) and fluorescence microscopy (Olympus BX50WI). Sharp microelectrodes were pulled from borosilicate glass capillaries to $\sim 70$ $\mathrm{M} \Omega$ (measured with $1 \mathrm{~m} \mathrm{KCl}$ ). The electrode tip was filled with $1 \%$ DiI in $100 \%$ ethanol. The rest of the electrode was then filled with 100\% ethanol. After penetrating the cell body with the electrode, dye was expelled by 1-50 nA positive current using the Master- 8 pulse generator and Iso-Flex electrostimulator (A.M.P.I.) for 1-3 min depending on cell size. Sections were then fixed in $4 \%$ paraformaldehyde overnight. For morphology analysis of the $\mathrm{GFP}^{+}$DiI-filled pyramidal neurons, threedimensional reconstructions of the cell body and dendritic processes were made from $Z$-series stacks of confocal images. The images were collapsed, the cell body was semiautomatically traced with NIH ImageJ (http://rsb.info.nih.gov/ij/), and the area of the traced soma was calculated. Quantifications of primary dendrites were made from the threedimensional reconstructed images and $Z$-series stacks. Spine densities were calculated by counting the number of spines on a highmagnification collapsed $Z$-stack and dividing the total spine by the length of the dendrite. Spine lengths were calculated using the measuring function in NIH ImageJ. The distributions of the primary dendrite number of each individual neuron under different conditions are shown as cumulative distribution plots (see Fig. 4C). A total of 25 neurons from four animals injected with $N k c c 1$-shRNA and 6 neurons from three animals injected with DsRed-shRNA were analyzed at 2 weeks. A total of 30 neurons from four animals injected with $N k c c 1$-shRNA and 19 neurons from four animals injected with DsRed-shRNA were analyzed at 3 weeks. Statistical significance $(p<0.05)$ between control and experimental groups was assessed using the Student's $t$ test.

Electrophysiology. Electroporated postnatal mice at different ages were anesthetized and processed for slice preparation as described previously (Owens et al., 1996). The brains were quickly removed into ice-cold CSF (ACSF) containing (in mM) $124 \mathrm{NaCl}, 5 \mathrm{KCl}, 1.25 \mathrm{NaH}_{2} \mathrm{PO}_{4}, 1 \mathrm{MgSO}_{4}, 2$ $\mathrm{CaCl}_{2}, 26 \mathrm{NaHCO}_{3}$, and 10 glucose oxygenated with $95 \% \mathrm{O}_{2}-5 \% \mathrm{CO}_{2}$, $\mathrm{pH}$ 7.4. Brains from postnatal day 0 (P0) to $\mathrm{P} 5$ animals were embedded in $4 \%$ low-melting-point agarose in ACSF, hardened on ice, and cut into coronal slices ( $300 \mu \mathrm{m}$ thick) using a Vibratome (Leica VT1000S). Brains from older animals were cut directly on the vibratome, and sections were confined to the sensorimotor regions of the cortex. Electrophysiological recordings were obtained at room temperature from sections continuously superfused with oxygenated ACSF. GFP ${ }^{+}$pyramidal neurons were visualized by DIC and fluorescence microscopy and were identified by their green fluorescence, location within layer II/III of cortex, neuronal morphology, and current profile in response to $20 \mathrm{mV}$ voltage steps. Microelectrodes (6-8 $\mathrm{M} \Omega$ resistance) were pulled from borosilicate glass capillaries and filled with the following solution (in $\mathrm{mm}$ ): $130 \mathrm{KCl}, 5$ $\mathrm{NaCl}, 0.4 \mathrm{CaCl}_{2}, 1 \mathrm{MgCl}_{2}, 10$ HEPES, pH 7.3, 11 EGTA, and 0.1\% Lucifer yellow for the majority of the recordings. For perforated patch recordings, the gramicidin stock $(10 \mathrm{mg} / \mathrm{ml}$ in DMSO $)$ was diluted in the internal pipette solution above to a final concentration of $25 \mu \mathrm{g} / \mathrm{ml}$. The tip of the pipette was filled with the gramicidin-containing solution, and the rest was filled with normal internal pipette solution. Gigaohm seals were made, and cells were applied in voltage ramps from -140 to $+100 \mathrm{mV}$ every $20 \mathrm{~s}$ to monitor current changes. After ramp currents stabilized, $3 \mathrm{~s}$ focal application of $100 \mu \mathrm{M}$ GABA (Research Biochemicals) was applied using the DAD superperfusion system (ALA Scientific) to activate $\mathrm{GABA}_{\mathrm{A}}$ Rs on the $\mathrm{GFP}^{+}$neurons. Voltage ramps from -140 to $+100 \mathrm{mV}$ were applied before and after GABA application. The resulting currents were then subtracted, and the difference were plotted as $I-V$ curves (see Fig. $1 B) . E_{G A B A}$ was determined for each cell as $x$-intercept of $I-V$ curves. To characterize spontaneous postsynaptic currents (sPSCs), 5-20 min of whole-cell recordings were made using a Double Patch-clamp EPC9/2 (HEKA Elektronik) at $10 \mathrm{kHz}$. The series and input resistances were monitored, and only those that changed $<20 \%$ during experiments were used for data analysis. Traces were analyzed using Igor Pro or MiniAnalysis (Synaptsoft) programs. Each synaptic event was manually selected based on rise time, amplitude, and decay properties. Additional drugs were added as indicated with the following estimated final concentrations: bicuculline methiodide (100 $\mu \mathrm{M}$; Sigma), DNQX (20 $\mu \mathrm{M}$; Tocris), and tetrodotoxin (TTx; $0.5 \mu \mathrm{M}$; Calbiochem). To characterize NMDA channel currents, outside-out patches were formed by slowly pulling the pipettes out of the slice after whole-cell recording. NMDA $(30 \mu \mathrm{M})$ or glutamate (100 $\mu \mathrm{M}$; Sigma) was applied to patches, and recordings were performed in ACSF containing TTx $(0.5 \mu \mathrm{M})$, bicuculline methiodide (50 $\mu \mathrm{M})$, DNQX (10 $\mu \mathrm{M})$, and glycine (40 $\mu \mathrm{M}$; Sigma). Unless otherwise noted, the holding potential for voltage-clamp recordings was $-70 \mathrm{mV}$. Statistical significance $(p<0.05)$ between control and experimental groups was assessed using a two-tailed Student's $t$ test.

\section{Results}

Acute knockdown of NKCC1 in newborn cortical neurons

To study the role of GABA in the development of cortical circuitry, we used an RNA interference (RNAi) strategy to knock- 

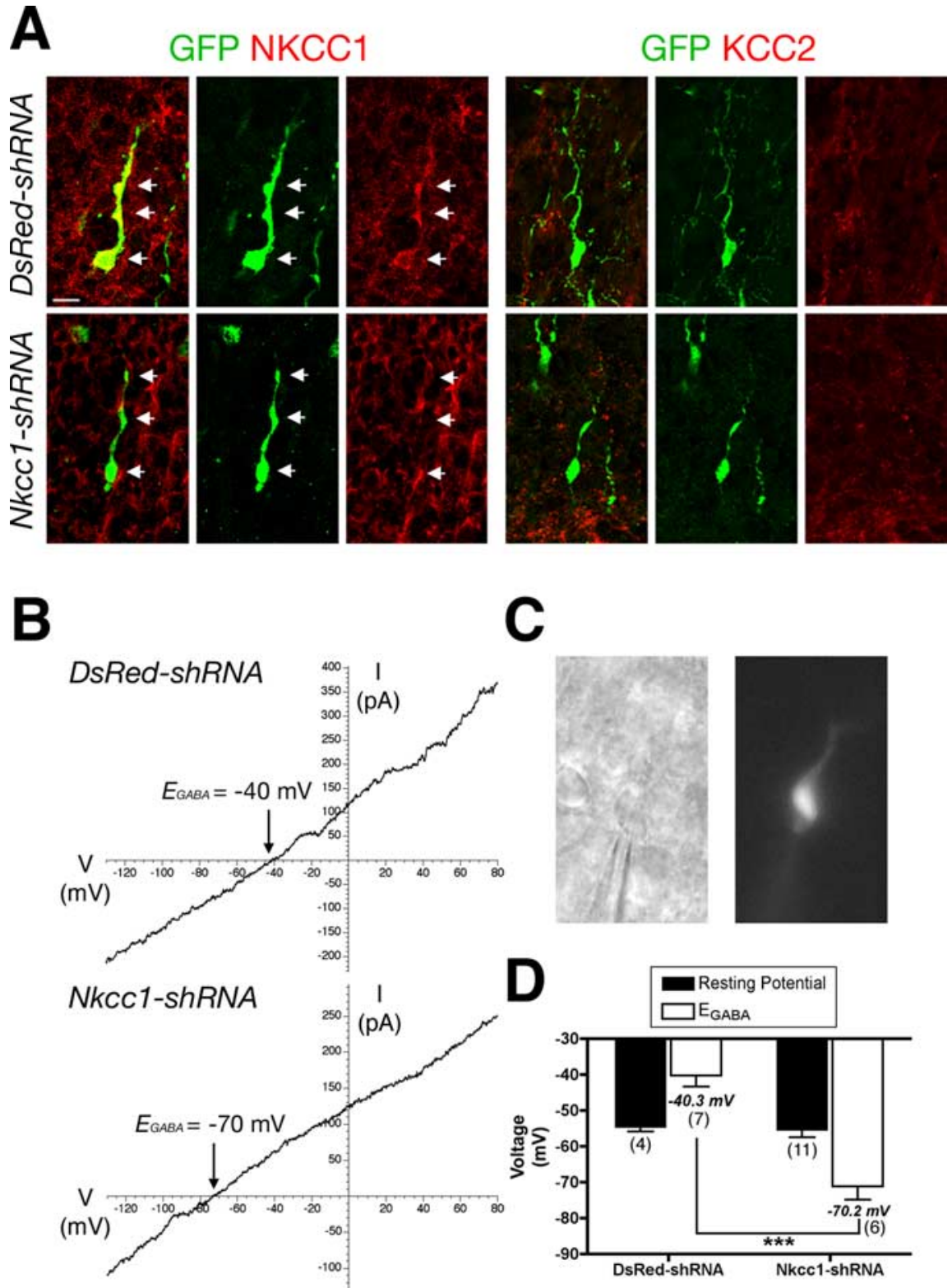

Figure 1. In vivo knockdown of NKCC1 alters GABA reversal potential of newborn neurons. $A, P 0$ cortical neurons electroporated with plasmids expressing GFP and shRNAs against either DsRed (control) or Nkcc1. Expression of Nkcc1-shRNA, but not the control shRNA (DsRed-shRNA), reduced NKCC1 expression in newborn pyramidal cells. KCC2 staining showed no change in expression level in GFP ${ }^{+}$neurons. Arrows highlight staining in cell body and process varicosities. Scale bar, $10 \mu \mathrm{m}$. $\boldsymbol{B}$, Voltage ramps obtained from PO cortical neurons expressing either DsRed-shRNA or Nkcc1-shRNA under gramicidin-perforated patch-clamp conditions. $E_{G A B A}$ reversed at more hyperpolarized potentials with expression of Nkcc1-shRNA than controls (as indicated by the $x$-intercept). C, PO GFP ${ }^{+}$cell observed under DIC (left) and fluorescence (right) microscopy in acute brain slices. D, Expression of Nkcc1-shRNA effectively changed the chloride gradient in newborn cortical neurons, making GABA hyperpolarizing to the $V_{\text {rest }}$ instead of depolarizing in control cells. Bar graphs indicate mean \pm SEM ( ${ }^{* * *} p<0.0001, t$ test). The numbers of recorded cells are indicated in parentheses.

down the expression of $\mathrm{NKCC} 1, \mathrm{a} \mathrm{Cl}^{-}$importer responsible for GABA-induced depolarization in immature neurons (Delpire, 2000). We performed in utero electroporation of plasmids coexpressing GFP and a previously characterized shRNA against $N k c c 1$ in 15-d-old embryonic mice, during the birth of mid- to upper-layer cortical neurons (Ge et al., 2006). In utero RNAi provides both temporal and spatial control over loss of function and bypasses the pitfalls of potential genetic compensations often observed in knock-out animals. To test the ability of the shRNAs to knockdown endogenous NKCC1 protein in newborn neurons in the developing cortex, we performed immunohistochemistry of $\mathrm{GFP}^{+}$cells in electroporated cortices of neonatal (P0) mice. Nkccl-shRNA, but not control shRNA, reduced the expression of NKCC1 in immature cortical neurons without affecting the expression of $\mathrm{KCC} 2, \mathrm{a} \mathrm{Cl}^{-}$exporter expressed after birth and maintained through adulthood to make GABA hyperpolarizing (Fig. 1A). We further tested the efficacy of $N k c c 1$-shRNA by gramicidin-perforated patch recording of electroporated neurons at $\mathrm{P} 0$ to measure the intracellular $\mathrm{Cl}^{-}$concentration without perturbing the $\mathrm{Cl}^{-}$gradient. The GABA reversal potential $\left(E_{G A B A}\right)$ was significantly more negative in Nkccl-shRNAexpressing neurons than in control neocortical neurons (DsRed-shRNA, $-40.29 \pm 3.10 \mathrm{mV} ; \quad$ Nkccl-shRNA, $-71.17 \pm 3.77 \mathrm{mV} ; p<0.0001$ ) (Fig. $1 B, D)$. Given the unchanged resting membrane potential of electroporated cortical neurons at P0 (DsRed-shRNA, $-54.75 \pm 1.18 \mathrm{mV}$; Nkccl-shRNA, $-55.45 \pm 2.01 \mathrm{mV}$ ), GABA hyperpolarized cells expressing $N k c c 1$-shRNA, thus validating the effectiveness of RNAi knockdown to abolish GABA-induced depolarization (Fig. 1D).

\section{GABA regulates synaptic integration of} newborn cortical neurons

To test the ability of newborn cortical neurons to develop synaptic connections in the absence of GABA-induced depolarization in vivo, we recorded sPSCs in electroporated $\mathrm{GFP}^{+}$neurons at a holding potential of $-70 \mathrm{mV}$ in the presence of TTx $(0.5 \mu \mathrm{M})$. As newborn cortical neurons mature, they sequentially receive inhibitory and excitatory synaptic inputs that can be measured in the form of sPSCs (Owens et al., 1999; Tyzio et al., 1999; Hennou et al., 2002). In the first postnatal week, control $\mathrm{GFP}^{+}$neurons exhibited few sPSCs, all of which were blocked by bicuculline and therefore GABAergic (Fig. $2 A, B)$. However, we could not detect any sPSCs in Nkcc1-shRNA-expressing cells at this time (Fig. 2A,B). By the second and third postnatal week, the total frequencies of sPSCs in control cells had increased significantly (Fig. $2 A, B$ ), yet $N k c c 1$-shRNA neurons had sPSC frequencies at 11 and $42 \%$ of those observed in respective control cells, indicating defects in synaptic integration of Nkccl-shRNAexpressing neurons ( $t$ test; DsRed-shRNA vs Nkccl-shRNA; 2 weeks: $1.93 \pm 0.25$ vs $0.22 \pm 0.05 \mathrm{~Hz}, p<0.0001$; 3 weeks: $3.62 \pm$ 0.64 vs $1.51 \pm 0.36 \mathrm{~Hz}, p=0.0053$ ) (Fig. $2 C$ ).

We next investigated the type of synaptic transmission that the newborn cortical neurons receive after integration of cortical circuitry. Previous studies have shown that cortical neurons undergo the sequential development of GABA, followed by AMPA 


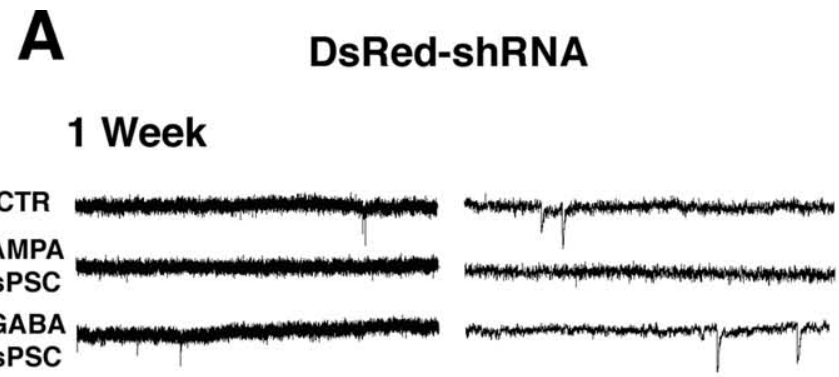

2 Weeks

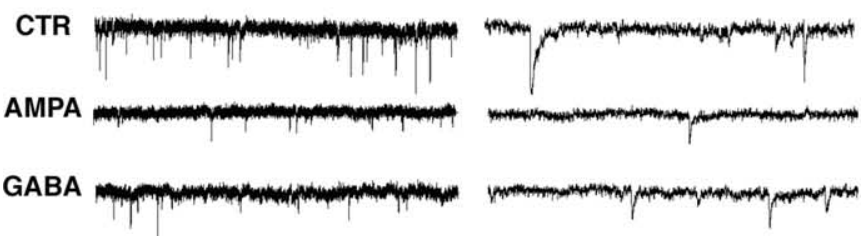

3 Weeks

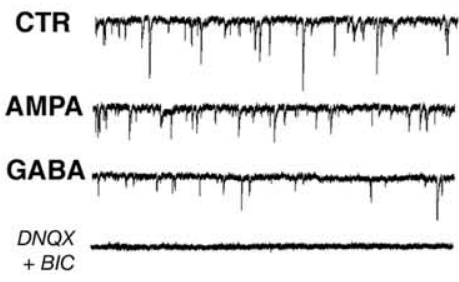

C

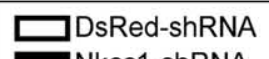

Nkcc1-shRNA

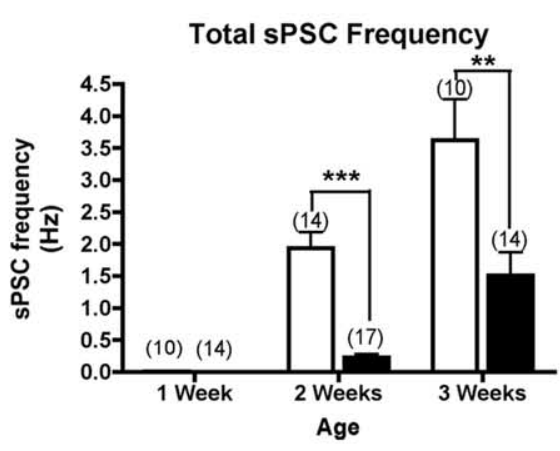

Figure 2. GABA regulates synaptic integration of cortical neurons and balance of excitatory and inhibitory inputs. $A, B$, Current traces of sPSCs in GFP ${ }^{+}$neurons at $1-3$ weeks postnatal in cells expressing control shRNA $(\boldsymbol{A})$ or Nkcc1-shRNA $(\boldsymbol{B})$. Traces on the right represent a shorter time course of traces on the left. Cells were recorded at a $-70 \mathrm{mV}$ holding potential and in $0.5 \mu \mathrm{m}$ TTx. AMPA and GABA sPSCs were isolated with bath application of $100 \mu \mathrm{m}$ bicuculline (BIC) and $20 \mu \mathrm{m}$ DNQX, respectively. Application of both drugs completely eliminated all sPSCs. CTR, Control. $\boldsymbol{C}-\boldsymbol{E}$, Average frequency of total sPSCS ( $\boldsymbol{C}$, AMPA sPSCs $(\boldsymbol{D})$, and GABA sPSCS $(\boldsymbol{E})$ for control and Nkcc1-shRNA cells. The fractions of total sPSCs that are AMPAergic $(\boldsymbol{D}$, right) and GABAergic ( $\boldsymbol{E}$, right) show that Nkcc1-shRNA expression disrupts development of AMPA synapses in the newborn pyramidal cells. Bar graphs indicate mean \pm SEM (*** $p<0.001 ;{ }^{* * *} p<0.0001 ; t$ test). The numbers of recorded cells are indicated in parentheses.

\section{Week}

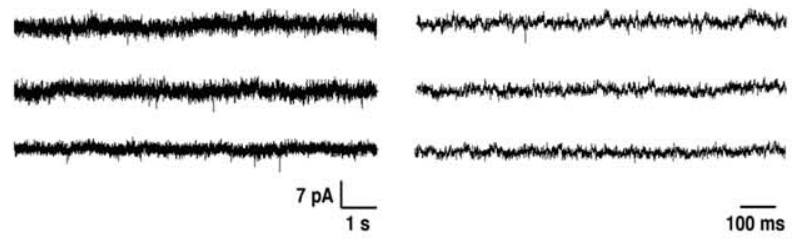

\section{Weeks}
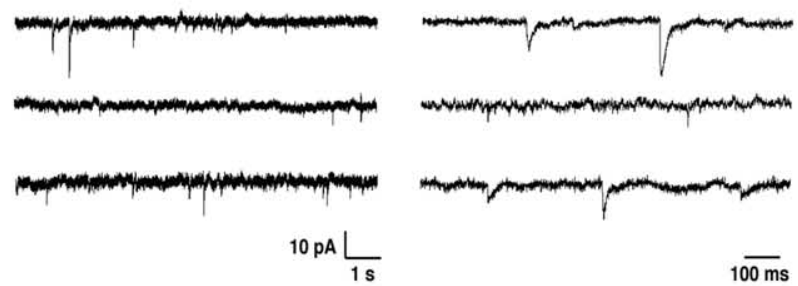

3 Weeks
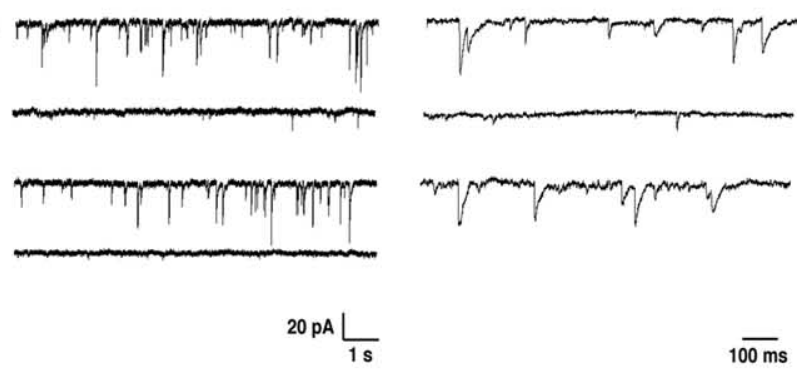

AMPA/Total sPSCs

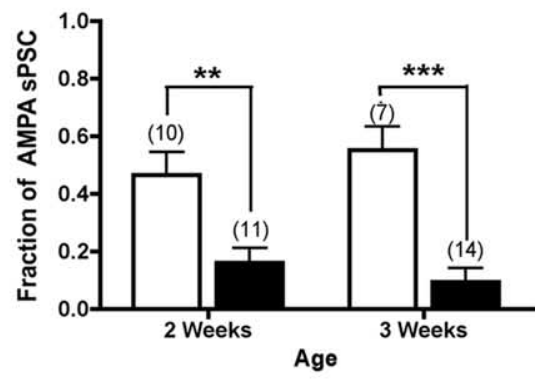

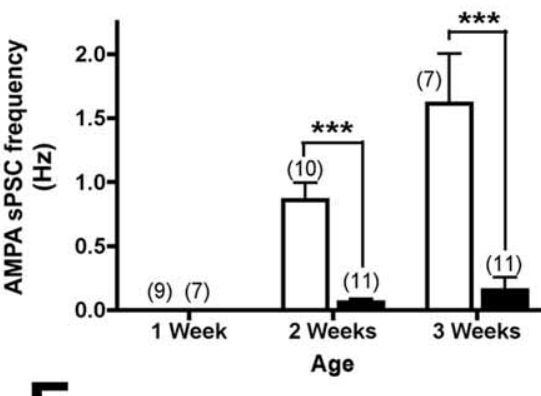

GABA/ Total sPSCs
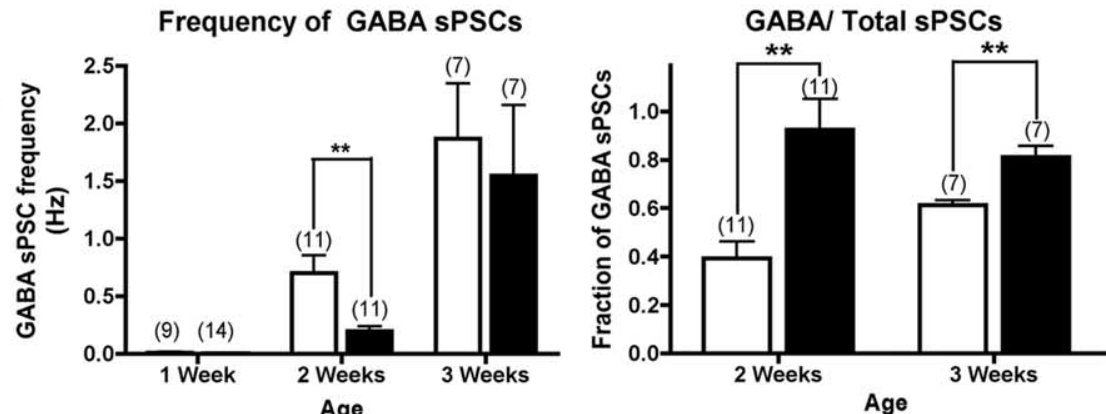
synapses (Chen et al., 1995; Khazipov et al., 2001; Hennou et al., 2002). To isolate the AMPA and GABAergic sPSCs, we bath applied the $\mathrm{GABA}_{\mathrm{A}} \mathrm{R}$ antagonist bicuculline methiodide $(100 \mu \mathrm{M})$ and non-NMDA glutamate receptor antagonist DNQX $(20 \mu \mathrm{M})$, respectively (Fig. $2 A$ ). In control $\mathrm{GFP}^{+}$cells, the newborn neurons followed the previously characterized sequential development of GABA - and AMPA - synaptic innervation, whereby all sPSCs were GABAergic in the first postnatal week, but AMPAmediated sPSCs appeared by 2 weeks and increased in frequency by 3 weeks (Fig. 2A) (Owens et al., 1999; Tyzio et al., 1999; Hennou et al., 2002). In contrast, in the Nkccl-shRNA-expressing neurons, there was marked reduction in the frequency of AMPAmediated synaptic transmission at 2 and 3 weeks ( $t$ test; DsRedshRNA vs Nkccl-shRNA; 2 weeks: $0.86 \pm 0.14$ vs $0.06 \pm 0.03 \mathrm{~Hz}$, $p<0.0001 ; 3$ weeks: $1.61 \pm 0.39$ vs $0.16 \pm 0.10 \mathrm{~Hz}, p=0.0005$ ) (Fig. $2 D$ ). The fractions of total synaptic currents that are AMPA mediated in Nkcc1-knockdown neurons were significantly reduced compared with that of controls ( $t$ test; DsRed-shRNA vs Nkccl-shRNA; 2 weeks: $0.46 \pm 0.08$ vs $0.16 \pm 0.05, p=0.0046 ; 3$ weeks: $0.55 \pm 0.08$ vs $0.09 \pm 0.05, p<0.0001$ ) (Fig. $2 D$ ). Interestingly, the frequency of GABA sPSCs in knockdown neurons was significantly reduced at 2 weeks but reached normal levels by 3 weeks ( $t$ test; DsRed-shRNA vs Nkcc1-shRNA; 2 weeks: $0.70 \pm$ 0.15 vs $0.20 \pm 0.04 \mathrm{~Hz}, p=0.0042$; 3 weeks: $1.87 \pm 0.48$ vs $1.55 \pm$ $0.61 \mathrm{~Hz}, p=0.6885$ ) (Fig. $2 E$ ). In fact, nearly all of the sPSCs at 2 and 3 weeks, 92 and $81 \%$, respectively, were GABAergic in Nkcc1shRNA neurons ( $t$ test; DsRed-shRNA vs Nkcc1-shRNA; 2 weeks: $0.39 \pm 0.07$ vs $0.92 \pm 0.13, p=0.0013$; 3 weeks: $0.61 \pm 0.02$ vs $0.81 \pm 0.05, p=0.0018$ ) (Fig. $2 E$ ). The change in sPSC frequency was not accompanied by a significant change in the mean amplitude of sPSCs ( $t$ test; DsRed-shRNA vs Nkccl-shRNA; 1 week: $2.4 \pm 1.3$ vs $1.1 \pm 0.8 \mathrm{pA}, p=0.3575 ; 2$ weeks: $23.5 \pm 5.7$ vs $16.4 \pm 3.0 \mathrm{pA}, p=0.2592$; 3 weeks: $27.3 \pm 6.4$ vs $34.0 \pm 7.1 \mathrm{pA}$, $p=0.5112$ ) (supplemental Fig. $1 A-C$, available at www. jneurosci.org as supplemental material), suggesting that there were no general defects in receptor expression at synapses.

To determine the specificity of the RNAi knockdown, we attempted to rescue the reduced AMPA current phenotype by electroporating the $N k c c 1$-shRNA together with a plasmid expressing the wild-type mouse $N k c c 1$ cDNA. Whereas coelectroporation of $N k c c 1$-shRNA with a control yellow fluorescent protein (YFP)expressing plasmid had no effect on the Nkccl-shRNA phenotype, expression of the wild-type $N k c c 1$ in the same molar ratio as the control conditions rescued the fraction of AMPA- and GABA-mediated sPSCS both at 2 weeks ( $t$ test; $N k c c 1$-shRNA vs $N k c c 1$; AMPA: $0.16 \pm 0.05$ vs $0.50 \pm 0.06, p=0.0003$; GABA: $0.92 \pm 0.13$ vs $0.46 \pm 0.05, p=0.0054)$ and 3 weeks ( $t$ test; Nkcc1-shRNA vs Nkccl; AMPA: $0.12 \pm 0.06$ vs $0.68 \pm 0.07, p<$ 0.0001 ; GABA: $0.81 \pm 0.05$ vs $0.42 \pm 0.08, p=0.0014$ ) (supplemental Fig. $2 A, B$, available at www.jneurosci.org as supplemental material). Together, these findings indicate that reducing GABA-induced excitatory signaling in neurons during development results in defective synaptic development. Our findings also indicate that this perturbation is specifically attributable to reduced excitatory input and altered relative proportions of excitatory and inhibitory inputs on individual neurons.

\section{Blocking NKCC1 with bumetanide disrupts excitatory synapse development in the cortex}

Bumetanide, a selective NKCC1 inhibitor, has been demonstrated to suppress certain forms of epileptiform activity in vitro and in vivo, presumably by attenuating the depolarizing effect of GABA (Dzhala et al., 2005; Kilb et al., 2007). We gave daily intra- peritoneal injections of either bumetanide $(0.2 \mathrm{mg} / \mathrm{kg})$ or PBS saline to pregnant dams and their pups from E15 until P7 to assess the effects of bumetanide on the developing nervous system. Gramicidin-perforated patch recording of P0 cortical neurons from either bumetanide- or saline-injected mice confirmed that bumetanide could shift $E_{G A B A}$ toward a more hyperpolarizing potential ( $t$ test; control vs bumetanide; $-40.94 \pm 2.76$ vs $-66.07 \pm 3.87 \mathrm{mV} ; p<0.0001$ ) (Fig. $3 A-C$ ). Recording sPSCs in layer II/III cortical neurons from bumetanide-treated and control mice showed that the overall sPSC frequency was not significantly changed at 2 weeks ( $t$ test; control vs bumetanide; $1.8 \pm$ 0.2 vs $1.4 \pm 0.2 \mathrm{~Hz} ; p=0.1283$ ) but was significantly decreased at 4 weeks ( $t$ test; control vs bumetanide; $4.3 \pm 0.5$ vs $3.1 \pm 0.4 \mathrm{~Hz}$; $p=0.0141$ ) (Fig. 3D). Importantly, there was a significant reduction in AMPA sPSC frequency at 2 and 4 weeks, whereas GABA sPSC frequency was unaltered ( $t$ test; control vs bumetanide; AMPA frequency: 2 weeks, $0.8 \pm 0.1$ vs $0.3 \pm 0.1 \mathrm{~Hz}, p=0.0008$; 4 weeks, $1.9 \pm 0.3$ vs $0.2 \pm 0.1 \mathrm{~Hz}, p<0.0001$; GABA frequency: 2 weeks, $0.59 \pm 0.11$ vs $0.68 \pm 0.08 \mathrm{~Hz}, p=0.5405 ; 4$ weeks, $2.02 \pm 0.18$ vs $2.01 \pm 0.36 \mathrm{~Hz}, p=0.9741$ ) (Fig. $3 E, F$ ). Similarly, quantifying the proportion of total synaptic inputs that are excitatory or inhibitory revealed that bumetanide-treated animals exhibited a shift that tips the balance toward inhibition (Fig. $3 E, F)$. Together, these data suggest that systemic blockade of NKCC1 with bumetanide during the perinatal period can disrupt excitatory synapse formation in the cortex, resulting in an abnormal balance between excitatory and inhibitory activity in the adult brain.

\section{Nkcc1 knockdown disrupts morphology of cortical neurons}

To examine the effect of $N k c c 1$ knockdown on the morphology of newborn cortical neurons, we used DiI electrophoresis to fill $\mathrm{GFP}^{+}$neurons to label all their main branches and visualized their dendritic arbors in merged confocal stacks. At 2 and 3 weeks postnatal, control $\mathrm{GFP}^{+}$cells had the expected morphology of cortical pyramidal neurons with a basal axon and a thick, prominent apical dendrite (Fig. 4A). Compared with the control cells, Nkcc1-shRNA-expressing cells had a thinner apical dendrite that is effectively indistinguishable from other primary dendrites emanating from the cell body. Furthermore, Nkcc1-shRNAexpressing cells had significantly smaller cell bodies, 54 and 38\% reduction from soma sizes of the respective age-matched control cells ( $t$ test; DsRed-shRNA vs Nkcc1-shRNA; 2 weeks, $p<0.0001$; 3 weeks, $p<0.0001$ ) (Fig. $4 B$ ). In addition to the smaller cell body, Nkcc1-shRNA cells also exhibited fewer primary dendrites compared with control cells. At 2 weeks, whereas control neurons had between seven and eight primary dendrites, on average, the experimental GFP ${ }^{+}$cells had only four to five primary dendrites ( $t$ test; DsRed-shRNA vs Nkccl-shRNA; $p=0.0012$ ) (Fig. $4 C$ ). The reduction in primary dendrites in experimental $\mathrm{GFP}^{+}$cells persisted at 3 weeks postnatal ( $t$ test; DsRed-shRNA vs NkcclshRNA; $9.2 \pm 0.4$ vs $6.5 \pm 0.3 ; p<0.0001$ ) (Fig. $4 C$ ).

Given the substantial changes in synaptic physiology and cell morphology of $N k c c 1$-knockdown neurons, we investigated whether dendritic spines of newborn pyramidal neurons are also affected. We analyzed the mean spine density on secondary apical and basal dendrites of $\mathrm{GFP}^{+}$cells using confocal microscopy. We found that in the control neurons, average spine density increased from 0.53 to 0.62 spines/ $\mu \mathrm{m}$ as the neurons matured between weeks 2 and 3 . In contrast, the Nkcc1-shRNA-expressing cells showed a significant decrease in spine density compared with the controls, 0.26 and 0.40 spines $/ \mu \mathrm{m}$ at 2 and 3 weeks, respectively ( $t$ test; $D$ sRed-shRNA vs $N k c c 1$-shRNA; 2 weeks, $p<$ 
0.0001; 3 weeks, $p<0.0001$ ) (Fig. 5A,B). To further characterize the dendritic spines, we measured the length of the spines, which is indicative of synapse maturity as longer, thinner spines and filopodia contain fewer AMPA receptors (Matsuzaki et al., 2001). We found that spines on control $\mathrm{GFP}^{+}$neurons averaged 1.7 and $1.1 \mu \mathrm{m}$ at 2 and 3 weeks, whereas those of Nkccl-knockdown cells measured 2.2 and $1.4 \mu \mathrm{m}$ for the respective ages ( $t$ test; DsRed-shRNA vs Nkccl-shRNA; 2 weeks, $p<0.0001$; 3 weeks, $p<0.0001$ ) (Fig. $5 A, C)$. The decreased spine density and increased spine length in the experimental neurons correlates with the overall decrease in AMPA sPSC frequency, demonstrating that GABA activity plays a permissive role for the synaptic organization of newborn cortical neurons.

\section{GABA depolarization activates NMDA receptors to regulate excitatory synapse formation}

A long line of evidence suggests the importance of activity-dependent mechanisms in synapse formation at both the neuromuscular junction as well as the central synapse (Scheetz et al., 1997; Wu and Cline, 1998; Tao and Poo, 2005). In the developing brain, many glutamate synapses are initially AMPA-silent but can transmit NMDA receptor-mediated signaling (LoTurco et al., 1991). When presynaptic activity is paired with postsynaptic depolarization, the voltage-dependent $\mathrm{Mg}^{2+}$ block of the NMDA channel is relieved and AMPA signaling becomes active (Isaac et al., 1995; Liao et al., 1995; Xiao et al., 2004). Because GABA has an excitatory effect on developing neurons, we hypothesized that GABA may provide the depolarization necessary to activate the AMPA-silent synapses via an NMDA receptor-dependent mechanism. To test this hypothesis, we attempted to rescue the developmental defect of AMPA synapse formation in Nkcc1-knockdown cells with an NMDA receptor mutant that is less sensitive to the voltage-dependent block by $\mathrm{Mg}^{2+}$ and therefore not dependent on membrane depolarization induced by GABA (Wollmuth et al., 1998a,b). Outside-out patch recordings of wild-type $\mathrm{P} 0$ cortical neurons in the presence of 1 mM extracellular $\mathrm{Mg}^{2+}$ and $40 \mu \mathrm{M}$ glycine revealed the typical voltage-dependent $\mathrm{Mg}^{2+}$ block relieved by depolarization and blocked by NMDA receptor antagonist D-AP-5 (Fig. 6A). However, neurons electroporated with a previously characterized NMDA receptor mutant with an $\mathrm{N}+1 \mathrm{~S}$ substitution at the NR2A subunit revealed channel currents that lacked voltage-dependent block at negative holding potentials as described previously by Wollmuth et al. (1998b) (Fig. 6A,B).

Interestingly, when we coelectroporated $N k c c 1$-shRNA with the NR2Amut channel at E15, we found that the NR2Amut channel indeed rescued the reduced AMPA sPSCs observed in NkcclshRNA-expressing cells $(t$ test; Nkccl-shRNA vs $N k c c 1+$ NR2Amut; 2 weeks: $0.06 \pm 0.03$ vs $0.62 \pm 0.13 \mathrm{~Hz}, p=$
B C

Bumetanide
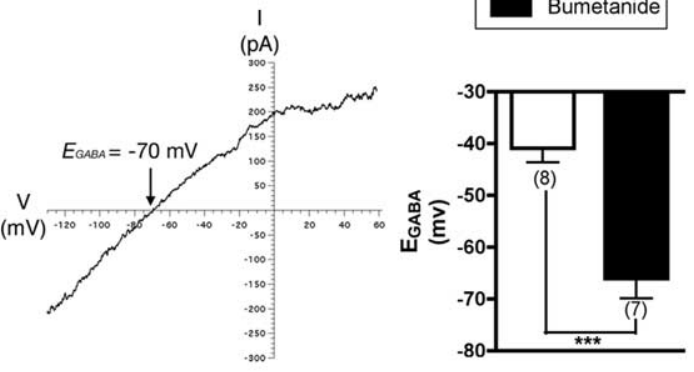

$\mathbf{E}$
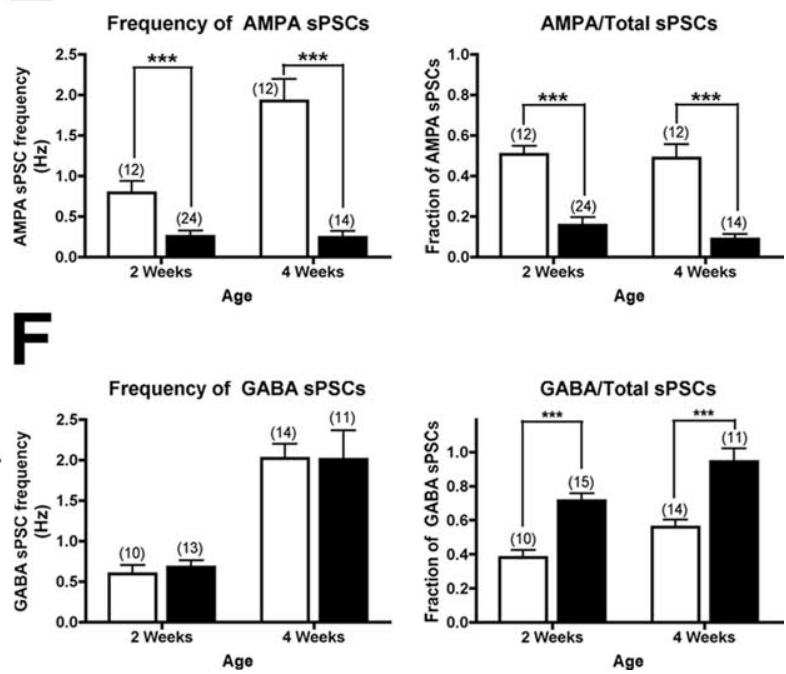

Figure 3. Bumetanide treatment disrupts excitatory synapse formation in vivo. $\boldsymbol{A}, \boldsymbol{B}$, Voltage ramps obtained from P0 cortical re hyperpolarized potentials in bumetanide-treated mice than in controls (as indicated by the $x$-intercept). C, Blocking NKCC

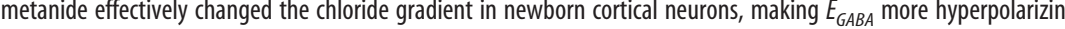
bumetanide treatment disrupts development of AMPA synapses in the newborn pyramidal cells. Bar graphs indicate mean \pm SEM $\left({ }^{*} p<0.05 ;{ }^{* * *} p<0.0001 ; t\right.$ test). The numbers of recorded cells are indicated in parentheses.

$0.0005 ; 3$ weeks: $0.16 \pm 0.10$ vs $0.80 \pm 0.16 \mathrm{~Hz}, p=0.0030$ ) (Fig $6 C, E)$. NR2Amut also rescued the decrease in GABA sPSC frequency observed in $N k c c 1$-knockdown neurons at 2 weeks $(t$ test; $N k c c 1$-shRNA vs $N k c c 1+$ NR2Amut; 2 weeks: $0.16 \pm 0.05$ vs $0.42 \pm 0.07 \mathrm{~Hz}, p=0.0001$; 3 weeks: $1.55 \pm 0.61$ vs $1.31 \pm 0.26$ $\mathrm{Hz}, p=0.6824$ ) (Fig. $6 D, F)$. Proportions of AMPA- and GABAmediated sPSCs in rescue neurons resembled those of control neurons and were significantly different from those in NkcclshRNA-expressing neurons both at 2 weeks ( $t$ test; $N k c c 1$-shRNA vs Nkcc1+NR2Amut; AMPA: $0.17 \pm 0.07$ vs $0.42 \pm 0.07, p=$ 0.0247; GABA: $0.92 \pm 0.13$ vs $0.59 \pm 0.06, p=0.0280)$ and 3 weeks ( $t$ test; $N k c c 1$-shRNA vs Nkccl + NR2Amut; AMPA: $0.12 \pm$ 0.06 vs $0.57 \pm 0.06, p<0.0001$; GABA: $0.81 \pm 0.05$ vs $0.65 \pm$ $0.05, p=0.0324$ ) (Fig. $6 C-F$ ). To confirm that the observed rescue was attributable to the voltage independence of NR2Amut, we coexpressed wild-type NR2A with Nkcc1-shRNA and analyzed the sPSCs. Interestingly, at 2 weeks, electroporation of NR2A was unable to rescue the decrease in AMPA synapse formation but was able to rescue the decrease in GABAergic $\mathrm{SP}$ SCs ( $t$ test; $N k c c 1$-shRNA vs NR2A; AMPA: $0.06 \pm 0.03$ vs $0.19 \pm$ $0.07 \mathrm{~Hz}, p=0.0714$, GABA: $0.20 \pm 0.04$ vs $0.71 \pm 0.19 \mathrm{~Hz}, p=$ 

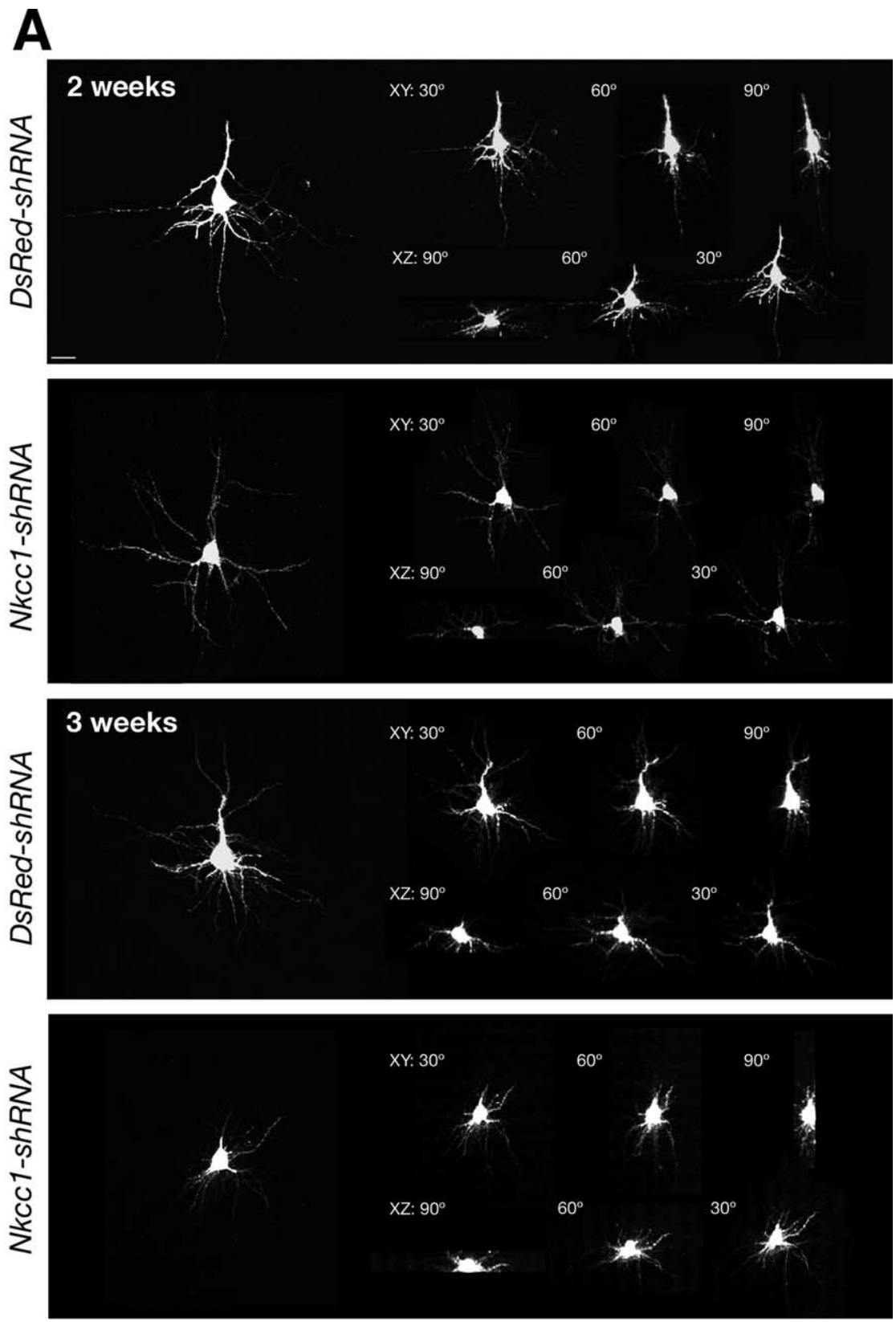

B

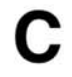

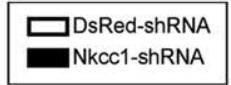

Soma Size

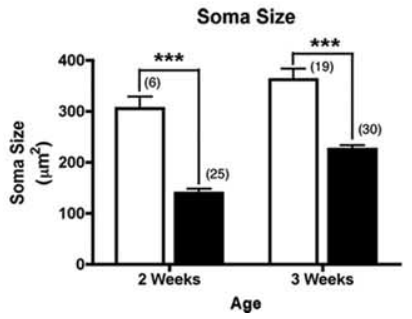

Primary Dendrites: 2 Weeks

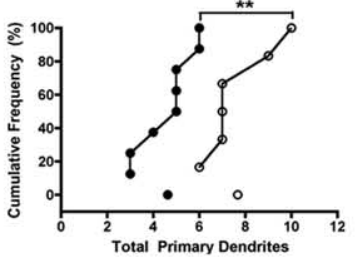

Primary Dendrites: 3 Weeks

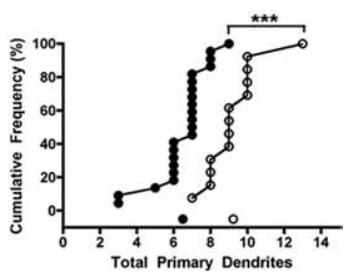

Figure 4. Nkcc1-shRNA expression disrupts morphology of cortical neurons. $\boldsymbol{A}$, Confocal three-dimensional reconstruction of dendrites of control or Nkcc 1-shRNA-expressing cortical neurons at 2 or 3 weeks postnatal. The left panels show the flattened stack of a neuron, and the right panels show multiple rotational views as indicated by the plane and angle of rotation. Scale bar, $20 \mu \mathrm{m}$. $\boldsymbol{B}, \boldsymbol{C}$, Quantification of average soma size $(\boldsymbol{B})$ and number of primary dendrites $(\boldsymbol{C})$ of GFP ${ }^{+}$cortical neurons demonstrate that, compared with control pyramidal neurons, Nkcc1-shRNA-expressing neurons display smaller soma size and fewer primary dendrites at both 2 and 3 weeks. Bar graphs indicate mean \pm SEM $\left({ }^{* *} p<0.005 ;{ }^{* * *} p<0.0001 ; t\right.$ test). The numbers of neurons are indicated in parentheses.
0.0030) (Fig. 6C,D), further suggesting that GABA and AMPA synapses develop by different mechanisms and that the development of AMPA synapses is uniquely dependent on NMDA receptor activation by GABA-mediated depolarization. To control for the effect of overexpressing NR2Amut, we electroporated NR2Amut with YFP and found that early expression of NR2Amut did not alter the frequency or proportion of AMPA and GABA sPSCs compared with control neurons at 3 weeks ( $t$ test; DsRed-shRNA vs NR2Amut:YFP; AMPA: $1.6 \pm 0.4$ vs $1.2 \pm 0.4 \mathrm{~Hz}, p=$ 0.4229; GABA: $1.9 \pm 0.5$ vs $1.0 \pm 0.2 \mathrm{~Hz}$, $p=0.1000$ ) (Fig. 6E,F). Thus, only the expression of an NMDA receptor that can be activated without membrane depolarization was able to restore the balance between excitatory and inhibitory synaptic inputs on the newborn neurons.

To also confirm that NMDA receptor activation during the period of GABA depolarization is critical for synapse development, we performed RNAi knockdown of NR1, the obligatory NMDA receptor subunit, to assess the effect on synaptic transmission in cortical neurons. To test the efficacy of NR1 knockdown, we recorded NMDA currents from 1-week-old cortical neurons of mice electroporated with NR1shRNA at E15. After a $5 \mathrm{~s}$ focal application of NMDA $(30 \mu \mathrm{M})$, control neurons from electroporated animals displayed large inward NMDA-mediated currents recorded from a holding potential of $-70 \mathrm{mV}$ and in the presence of $\mathrm{Mg}^{2+}$-free bath solution containing TTx $(0.5 \mu \mathrm{M})$, bicuculline (100 $\mu \mathrm{M})$, and DNQX $(20 \mu \mathrm{M})$ (Fig. 7A). However, NR1-shRNA-expressing neurons had drastically decreased current amplitudes in response to NMDA application compared with controls ( $t$ test; control vs NR1-shRNA; $64 \pm 3$ vs $8 \pm 3$ pA; $p<$ 0.0001) (Fig. 7A,B). Interestingly, NR1 knockdown during the period of GABA depolarization caused a decrease in total sPSC frequency at 2 weeks but not at 3 weeks ( $t$ test; DsRed-shRNA vs NR1shRNA; 2 weeks: $1.93 \pm 0.25$ vs $0.82 \pm$ $0.18 \mathrm{~Hz}, p=0.0017$; 3 weeks: $3.62 \pm 0.64$ vs $3.96 \pm 1.27 \mathrm{~Hz}, p=0.8011$ ) (Fig. $7 B$ ). Moreover, the decrease in synaptic transmission at 2 weeks was attributable to a selective failure to develop excitatory AMPA transmission, whereas GABA sPSCs were not significantly decreased ( $t$ test; DsRed-shRNA vs NR1-shRNA; AMPA: $0.86 \pm 0.17$ vs $0.29 \pm 0.09 \mathrm{~Hz}, p=0.0019$; GABA: $0.70 \pm 0.15$ vs $0.44 \pm 0.07 \mathrm{~Hz}, p=$ 0.2277 ) (Fig. 7C,D), similar to the effect of Nkcc1 knockdown. Together, this evidence strongly suggests a process in which 
GABA-induced depolarization through $\mathrm{GABA}_{\mathrm{A}} \mathrm{R}$ activation is required to induce the expression of AMPA synapses by activating NMDA receptors, supporting a Hebbian mechanism of synapse formation via an activity-dependent detection of both excitatory and inhibitory neurotransmission.

\section{Discussion}

A precise balance of excitatory glutamatergic and inhibitory GABAergic synaptic inputs onto mammalian cortical neurons is essential for the proper function of cortical circuits. We now provide evidence for an activity-dependent mechanism by which early depolarizing GABAergic inputs regulate the development of AMPA receptormediated glutamatergic synapses via an NMDA receptor-mediated process. First, using electrophysiological recordings, we show that abolishing GABA-mediated excitation in utero by RNAi knockdown and bumetanide block significantly reduces the development of AMPA receptormediated transmission in the first weeks after birth and persists into early adulthood. Second, we show through an array of morphological analysis that dendritic arbors as well as spine density and spine length are altered when GABA excitation is blocked. These observations provide additional evidence for a loss of glutamatergic transmission because these morphological changes most likely reflect responses of neurons to decreased AMPA transmission (Wu and Cline, 1998; Cline, 2001; CohenCory, 2002; Zhou et al., 2004; Haas et al., 2006). Third, we show that the Nkcc-RNAi phenotype is rescued by a mutant voltageindependent NMDA receptor and replicated by NR1 knockdown, indicating that the role of GABA in glutamatergic synaptic development is dependent on its ability to depolarize and activate voltage-dependent NMDA receptors.

The high intracellular chloride gradient in immature neurons has been observed in all species studied and thus is highly evolutionarily conserved (Owens et al., 1996; Khazipov et al., 2001; Akerman and Cline, 2006). Because GABA-mediated spontaneous synaptic activity develops before glutamatergic synaptic activity in the perinatal neocortex, these large and slow depolarizations may provide the first excitatory drive necessary for activitydependent synapse formation (Ben-Ari, 2006). By altering the chloride gradient of newborn cortical neurons in vivo, we demonstrate here that GABA-induced excitation via $\mathrm{GABA}_{\mathrm{A}} \mathrm{R}$ activation plays a permissive role in the formation of synaptic inputs on newborn cortical neurons. Our findings complement a recent study of newly generated granule neurons in the adult dentate gyrus, providing evidence that GABA-mediated excitation drives synaptic integration of newborn neurons in both embryos and adults (Ge et al., 2006). The depolarizing effects of GABA provide

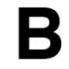

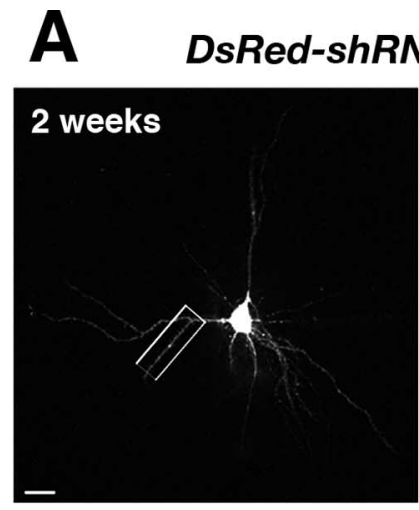
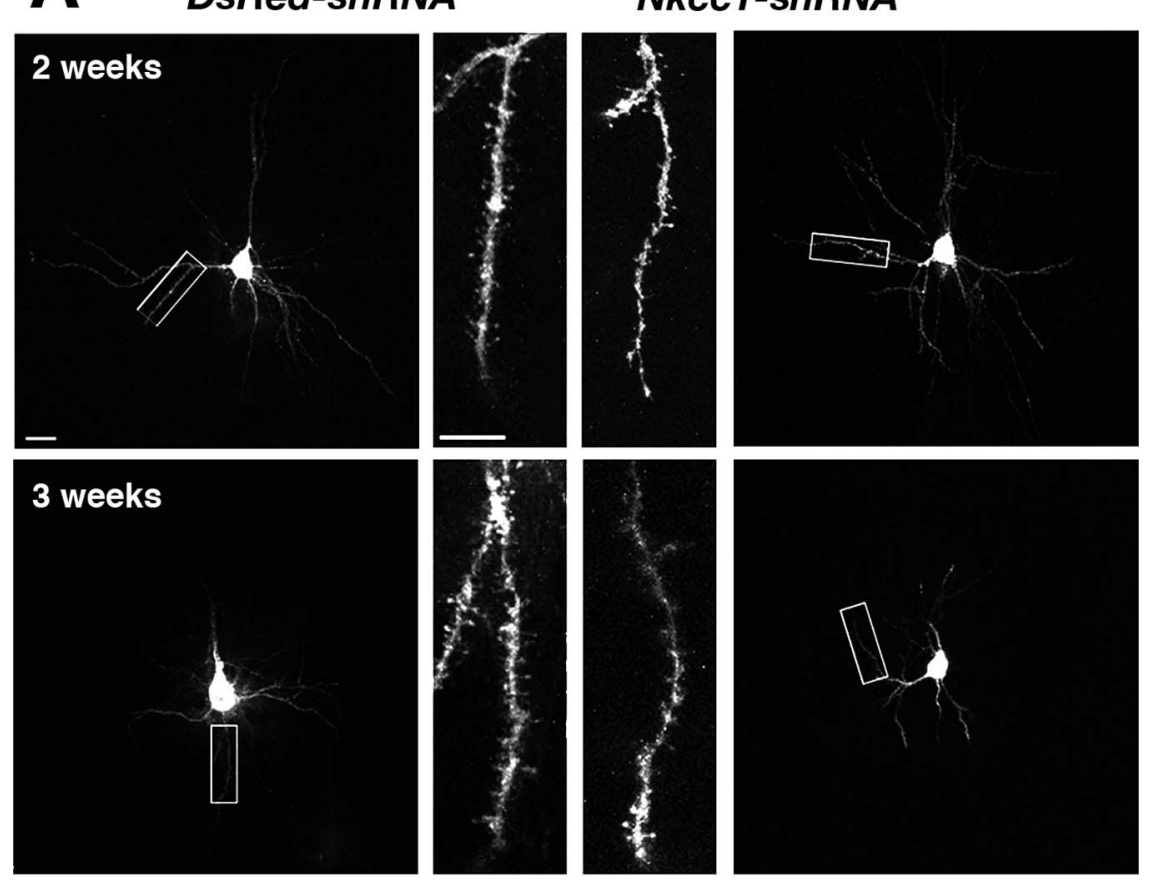

Average Spine Density

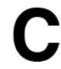

Average Spine Lengths

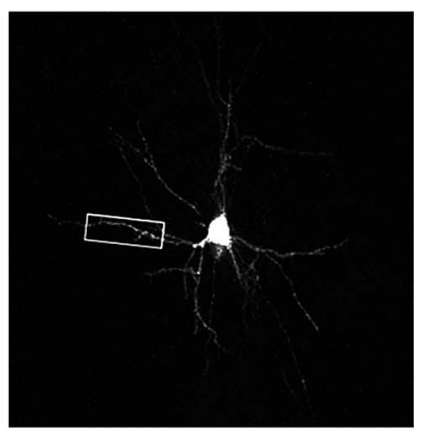

Figure 5. Nkcc1-shRNA expression disrupts synaptic spines of cortical pyramidal neurons. $\boldsymbol{A}$, Images of 2 and 3 week control or Nkcc1-shRNA-expressing cortical neurons. Cortical pyramidal are neurons filled with Dil for visualization of their dendritic spines on their secondary dendrites. Scale bars, $10 \mu \mathrm{m}$. B, Quantification of the average spine density shows that Nkcc1-shRNAonstrate that Nkcc1-knockdown cells have longer dendritic spines than that of control GFP ${ }^{+}$cells. Bar graphs indicate mean \pm SEM $\left({ }^{* * *} p<0.0001 ; t\right.$ test). The numbers of neurons $(\boldsymbol{B})$ or spines $(\boldsymbol{C})$ are indicated in parentheses.

a rational solution to the problem of equilibrating excitation and inhibition during brain maturation. Because $E_{G A B A}$ is closer to the resting membrane potential than $E_{\text {glutamate }}, \mathrm{GABA}_{\mathrm{A}} \mathrm{R}$ activation can drive action potentials and calcium influx without the toxic effects associated with glutamate overexcitation, thus modulating developmental processes without risking cell injury (BenAri, 2006).

The long-lasting effects (up to 4 weeks after birth) of disruptions in early GABA signaling seen here suggest that there may be a critical period for cortical synaptogenesis similar to the critical period for visual cortex plasticity (Hensch, 2005). Our findings seemingly contradict a previous study in which visual deprivation during a sensitive period in rat resulted in a net increase in excitatory and decrease in inhibitory synaptic drive in layer 4 neurons of the primary visual cortex (Maffei et al., 2004). However, the 
A

B

Control

$-70 \mathrm{mV}$

$-50 \mathrm{mV}$.

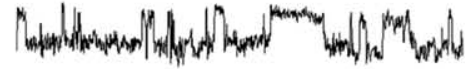

$0 \mathrm{mV}$

$30 \mathrm{mV}$

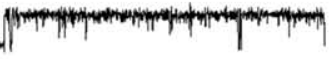

NMDA mut

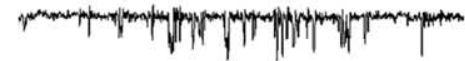

(4)

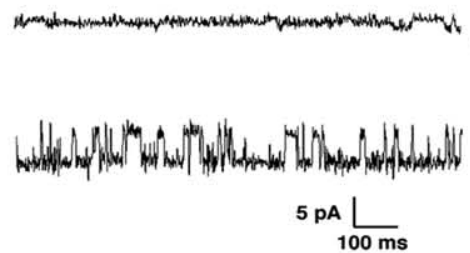

(4) $\underset{(\mathrm{mV})}{\text { Voltage }}$

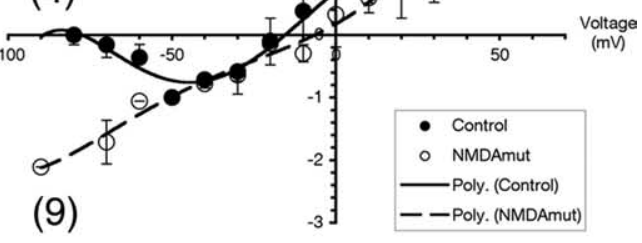

C

2 Weeks

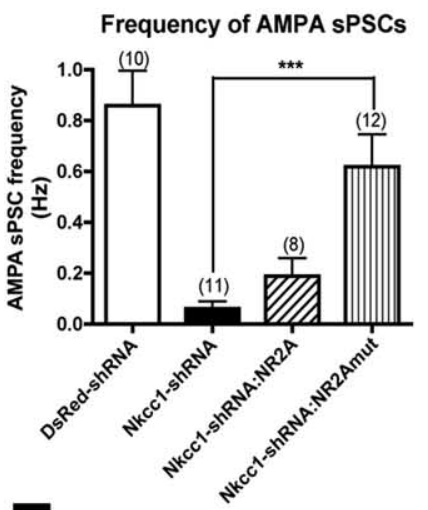

E

\section{Weeks}

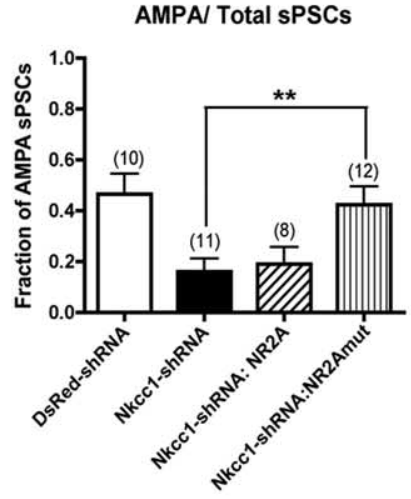

Frequency of AMPA sPSCs

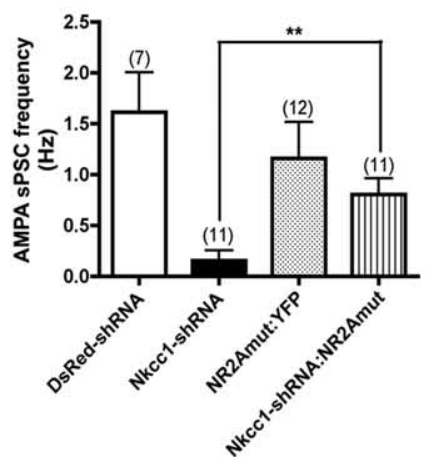

AMPA/ Total sPSCs

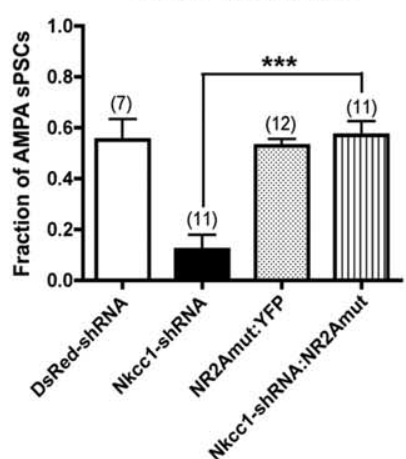

D

2 Weeks
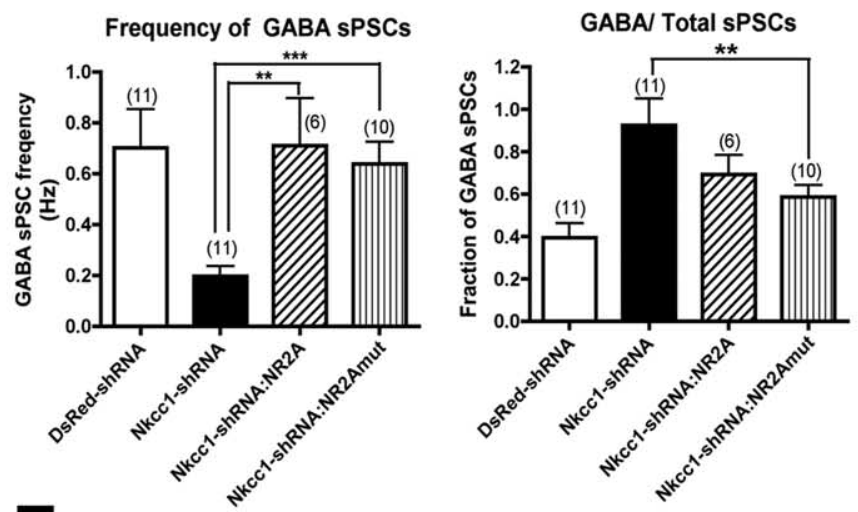

3 Weeks

Figure 6. Rescue of $N k c c 1$ knockdown with a voltage-independent NMDA receptor mutant. $A$, Outside-out patch recordings of PO control cortical neurons or neurons electroporated with the NR2A $\mathrm{N}+15 \mathrm{NMDA}$ receptor mutant (NR2Amut). Channels were recorded in the presence of $0.5 \mu \mathrm{m}$ TTX, $50 \mu \mathrm{m}$ bicuculline, $20 \mu \mathrm{m}$ DNQX, $40 \mu \mathrm{m}$ glycine, and $100 \mu \mathrm{m}$ glutamate. B, I-V curve of NMDA channels recorded from outside-out patches as seen in $A$ normalized to channel current at $-50 \mathrm{mV}$. Control neurons demonstrate the $\mathrm{Mg}^{2+}$-dependent block at hyperpolarized holding potentials, which was absent in neurons expressing the NMDAmut receptor. $C-F$, Coexpression of NMDAmut with Nkcc1-shRNA restored the frequency and proportion of AMPA and GABA sPSCS close to that of control neurons at 2 weeks $(\boldsymbol{C}, \boldsymbol{D})$ and 3 weeks $(\boldsymbol{E}, \boldsymbol{F})$, respectively. $\boldsymbol{C}, \boldsymbol{D}$, Expression of wild-type NR2A did not rescue the defect in AMPA synapse formation at 2 weeks caused by Nkcc 1 knockdown $(\boldsymbol{C})$ but was able to rescue the delay in GABA synapse formation $(\boldsymbol{D})$. $\boldsymbol{E}, \boldsymbol{F}$, Expression of NMDAmut with YFP did not change the frequency or proportion of AMPA $(\boldsymbol{E})$ and GABA $(\boldsymbol{F})$ sPSCS. Bar graphs indicate mean \pm SEM $\left({ }^{*} p<0.05 ;{ }^{* *} p<0.01 ;{ }^{* * *} p<0.0005 ; t\right.$ test). The numbers of recorded cells are indicated in parentheses.
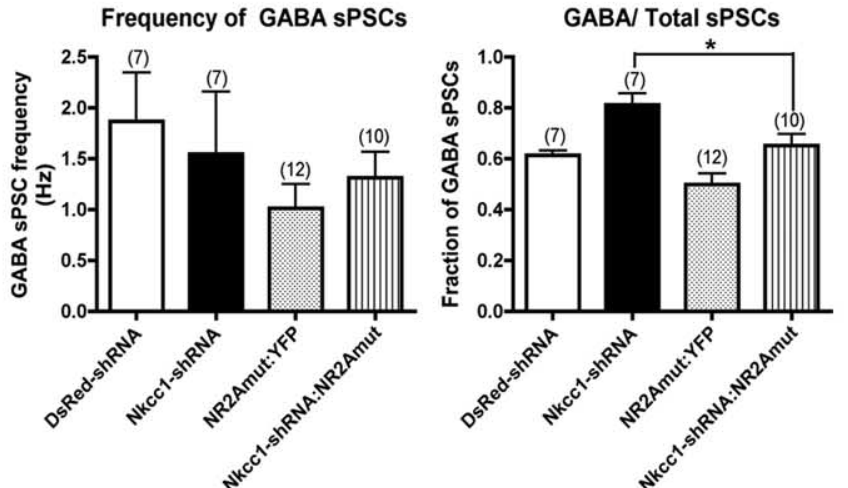
homeostatic responses seen by Maffei et al. (2004) occurred at a later stage (P15-P17) than our manipulations (E15-P7). We propose that because GABA-mediated spontaneous synaptic activity develops before glutamatergic synaptic activity in the perinatal neocortex, GABA depolarization may provide the first excitatory drive necessary for synapse formation. This has important implications for using the NKCC1 blocker bumetanide to treat neonatal seizures. A study by Dzhala et al. (2005) showed a clear therapeutic effect of bumetanide in treating neonatal seizures in rats by decreasing the excitatory effects of GABA, an observation that supports the use of bumetanide, an FDA-approved diuretic, for the treatment of neonatal seizures in humans. However, our data indicate that early bumetanide exposure during the period of GABA depolarization (E15-P7 in mice) produces a persistent clear disturbance in the formation of excitatory synapses in cortical neurons. Although neonatal seizures in humans typically abate after 3-4 d, prolonged inhibition of NKCC1 during the period of GABA depolarization ( 35-45 weeks after conception) might cause lasting changes in synapse formation, warranting future studies to investigate the possible adverse effects of bumetanide in treating neonatal seizures.

In addition to the physiological evidence for defective synaptic integration, changing early GABA-induced excitation to inhibition anatomically alters circuitry development. In a recent study, Cancedda et al. (2007) showed that reversing the excitatory effect of GABA in cortical neurons by premature expression of KCC2 results in fewer and shorter dendrites (Cancedda et al., 2007). Here, we confirm these findings by knocking down NKCC1 function and also demonstrate through electrophysiological recordings and analysis of spine morphology that glutamatergic synapse development is perturbed. Furthermore, we also provide a mechanism by which GABA exerts its role by activating NMDA receptors, confirming a previous study in which NR1 knockdown led to an increase in spine motility and eventual destabilization in spine structure and loss of excitatory synapses (Alvarez et al., 2007). Glutamatergic activity has been known to activate various downstream pathways involving factors such as Ras, Rho-GTPases, and CaMKII (calcium/calmodulin-dependent protein kinase II) to regulate dendritic arborization and synapse formation (Rajan and Cline, 1998; Li et al., 2000; Sin et al., 2002; Zhou et al., 2004). Furthermore, AMPA receptor-mediated transmission promotes dendritic arbor growth by mobilizing intracellular signaling cascades that stabilize and maintain branch formation (Wu et al., 1996; Rajan and Cline, 1998; Shi et al., 1999; Haas et al., 2006). Blocking glutamatergic synapse development has been shown to impair the growth of dendritic arbors by reducing branch stabilization (Haas et al., 2006). This suggests that the dendritic arbor defect observed in the present study as well as by Cancedda et al.
(2007) is likely a result of perturbed AMPA receptor-mediated synapse development. Future studies using time-lapse imaging to address the dynamics of the dendritic branches would shed more light on this process.

Perhaps most interestingly, we provide in vivo evidence that a neurotransmitter can regulate the balance between excitation and inhibition in a developing circuit. The balanced development of excitatory and inhibitory inputs has been identified as an activity-dependent process (Liu et al., 2004; Tao and Poo, 2005). A premature hyperpolarizing shift in the $\mathrm{Cl}^{-}$reversal potential has been shown to increase the ratio of inhibitory to excitatory inputs in Xenopus tectal neurons and rat cortical neurons in culture (Chudotvorova et al., 2005; Akerman and Cline, 2006). However, two questions had remained elusive: whether GABA regulates this balance in the developing mammalian cortex and what the mechanisms are that control this process. We now show that GABA regulates the formation of excitatory synapses in the mammalian cortex. In addition, our finding that depolarizing GABAergic transmission is required for the formation of glutamatergic synapses via $\mathrm{GABA}_{\mathrm{A}}$ Rs and NMDA receptor activation provides a mechanism for this process. Cortical neurons begin to express functional NMDA receptors when they migrate to the 


\section{A}
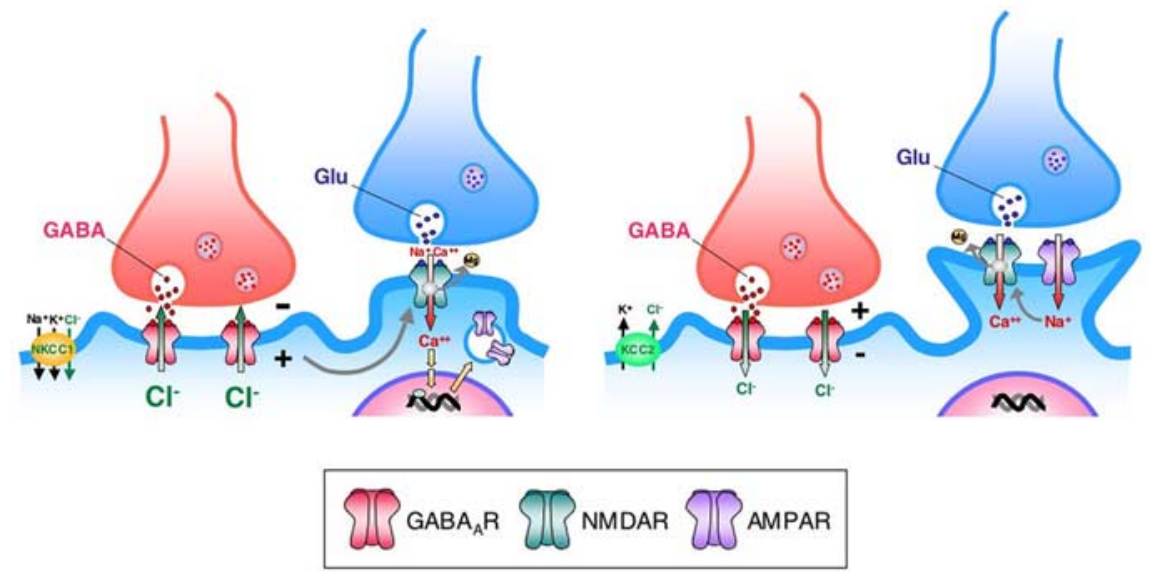

Figure 8. Proposed model for excitatory and inhibitory synapse matching. $\boldsymbol{A}$, An immature pyramidal cell (blue) expresses NKCC 1 to generate a high intracellular chloride concentration. A GABAergic interneuron (red) releases GABA and depolarizes the pyramidal cell after $\mathrm{GABA}_{A}$ R activation. $\mathrm{GABA}_{\mathrm{A}} \mathrm{R}$ activation relieves the $\mathrm{Mg}^{2+}$ block in the NMDA receptors, allowing $\mathrm{Ca}^{2+}$ entry. $\mathrm{Ca}^{2+}$ can activate signaling cascades, which ultimately results in the expression of AMPA receptors at the synaptic site. $\boldsymbol{B}$, The mature pyramidal neuron expresses $\mathrm{KCC}_{2}, \mathrm{a} \mathrm{K}^{+}-\mathrm{Cl}^{-}$cotransporter that generates a low intracellular chloride gradient, making GABA hyperpolarizing. AMPA receptors at the mature synapse can activate NMDA receptors to mediate synaptic plasticity. NMDAR, NMDA receptor; AMPAR, AMPA receptor; Glu, glutamate.

cortical plate, but these initial glutamatergic synapses are "silent" because of the $\mathrm{Mg}^{2+}$ block of NMDA receptors at the resting membrane potential (LoTurco et al., 1991; Akerman and Cline, 2006). GABAergic depolarization can facilitate relief of this voltage-dependent $\mathrm{Mg}^{2+}$ block and allow $\mathrm{Ca}^{2+}$ entry to initiate intracellular signaling cascades (Leinekugel et al., 1997). Our NR1 knockdown data confirm previous findings in which RNAi knockdown of NR1 in cultured hippocampal neurons led to an increase in synaptic spine motility, a decrease in spine stabilization, and an eventual loss of excitatory synapses (Alvarez et al., 2007). Whereas Alvarez et al. (2007) suggest that the physical interaction of the NR1 C-terminal tail is responsible for the longterm stabilization of synapse and spines, our data suggest that the ionotropic property of NMDA receptors is critical for excitatory synapse formation. The differences seen here may be attributable to experimental manipulations and timing of knockdown (in utero delivery of RNAi in vivo at E15 vs transfection of organotypic slice cultures of $\mathrm{P} 7$ rat hippocampus).

Cooperation with NMDA receptor activation represents an early form of coincidence detection between GABAergic and glutamatergic inputs. We propose a model in which GABA activation, reflecting the quantity of GABAergic (and eventually inhibitory) inputs onto the newborn neuron, permits the development of glutamatergic synapses (Fig. 8). Thus, the balance between excitation and inhibition is ensured from the beginning of synaptogenesis.

\section{References}

Akerman CJ, Cline HT (2006) Depolarizing GABAergic conductances regulate the balance of excitation to inhibition in the developing retinotectal circuit in vivo. J Neurosci 26:5117-5130.

Alvarez VA, Ridenour DA, Sabatini BL (2007) Distinct structural and ionotropic roles of NMDA receptors in controlling spine and synapse stability. J Neurosci 27:7365-7376.

Barbin G, Pollard H, Gaiarsa JL, Ben-Ari Y (1993) Involvement of GABAA receptors in the outgrowth of cultured hippocampal neurons. Neurosci Lett 152:150-154.
Ben-Ari Y (2006) Basic developmental rules and their implications for epilepsy in the immature brain. Epileptic Disord 8:91-102.

Cancedda L, Fiumelli H, Chen K, Poo MM (2007) Excitatory GABA action is essential for morphological maturation of cortical neurons in vivo. J Neurosci 27:5224-5235.

Chen G, Trombley PQ, van den Pol AN (1995) GABA receptors precede glutamate receptors in hypothalamic development; differential regulation by astrocytes. J Neurophysiol 74:1473-1484.

Chudotvorova I, Ivanov A, Rama S, Hubner CA, Pellegrino C, Ben-Ari Y, Medina I (2005) Early expression of KCC2 in rat hippocampal cultures augments expression of functional GABA synapses. J Physiol (Lond) 566:671-679.

Cline HT (2001) Dendritic arbor development and synaptogenesis. Curr Opin Neurobiol 11:118-126.

Cohen-Cory S (2002) The developing synapse: construction and modulation of synaptic structures and circuits. Science 298:770-776.

Delpire E (2000) Cation-chloride cotransporters in neuronal communication. News Physiol Sci 15:309-312.

Dzhala VI, Talos DM, Sdrulla DA, Brumback AC, Mathews GC, Benke TA, Delpire E, Jensen FE, Staley KJ (2005) NKCC1 transporter facilitates seizures in the developing brain. Nat Med 11:1205-1213.

Ge S, Goh EL, Sailor KA, Kitabatake Y, Ming GL, Song H (2006) GABA regulates synaptic integration of newly generated neurons in the adult brain. Nature 439:589-593.

Haas K, Li J, Cline HT (2006) AMPA receptors regulate experiencedependent dendritic arbor growth in vivo. Proc Natl Acad Sci USA 103:12127-12131.

Heck N, Kilb W, Reiprich P, Kubota H, Furukawa T, Fukuda A, Luhmann HJ (2007) GABA-A receptors regulate neocortical neuronal migration in vitro and in vivo. Cereb Cortex 17:138-148.

Hennou S, Khalilov I, Diabira D, Ben-Ari Y, Gozlan H (2002) Early sequential formation of functional GABA(A) and glutamatergic synapses on CA1 interneurons of the rat foetal hippocampus. Eur J Neurosci 16:197-208.

Hensch TK (2005) Critical period plasticity in local cortical circuits. Nat Rev Neurosci 6:877-888.

Isaac JT, Nicoll RA, Malenka RC (1995) Evidence for silent synapses: implications for the expression of LTP. Neuron 15:427-434.

Khazipov R, Esclapez M, Caillard O, Bernard C, Khalilov I, Tyzio R, Hirsch J, Dzhala V, Berger B, Ben-Ari Y (2001) Early development of neuronal activity in the primate hippocampus in utero. J Neurosci 21:9770-9781.

Kilb W, Sinning A, Luhmann HJ (2007) Model-specific effects of bumetanide on epileptiform activity in the in-vitro intact hippocampus of the newborn mouse. Neuropharmacology 53:524-533.

Leinekugel X, Medina I, Khalilov I, Ben-Ari Y, Khazipov R (1997) Ca2+ oscillations mediated by the synergistic excitatory actions of GABA(A) and NMDA receptors in the neonatal hippocampus. Neuron 18:243-255.

Li H, Tornberg J, Kaila K, Airaksinen MS, Rivera C (2002) Patterns of cation-chloride cotransporter expression during embryonic rodent CNS development. Eur J Neurosci 16:2358-2370.

Li Z, Van Aelst L, Cline HT (2000) Rho GTPases regulate distinct aspects of dendritic arbor growth in Xenopus central neurons in vivo. Nat Neurosci 3:217-225.

Liao D, Hessler NA, Malinow R (1995) Activation of postsynaptically silent synapses during pairing-induced LTP in CA1 region of hippocampal slice. Nature 375:400-404.

Liu L, Wong TP, Pozza MF, Lingenhoehl K, Wang Y, Sheng M, Auberson YP, Wang YT (2004) Role of NMDA receptor subtypes in governing the direction of hippocampal synaptic plasticity. Science 304:1021-1024.

Lois C, Hong EJ, Pease S, Brown EJ, Baltimore D (2002) Germline transmis- 
sion and tissue-specific expression of transgenes delivered by lentiviral vectors. Science 295:868-872.

LoTurco JJ, Blanton MG, Kriegstein AR (1991) Initial expression and endogenous activation of NMDA channels in early neocortical development. J Neurosci 11:792-799.

LoTurco JJ, Owens DF, Heath MJ, Davis MB, Kriegstein AR (1995) GABA and glutamate depolarize cortical progenitor cells and inhibit DNA synthesis. Neuron 15:1287-1298.

Maffei A, Nelson SB, Turrigiano GG (2004) Selective reconfiguration of layer 4 visual cortical circuitry by visual deprivation. Nat Neurosci 7:1353-1359.

Matsuzaki M, Ellis-Davies GC, Nemoto T, Miyashita Y, Iino M, Kasai H (2001) Dendritic spine geometry is critical for AMPA receptor expression in hippocampal CA1 pyramidal neurons. Nat Neurosci 4:1086-1092.

Noctor SC, Flint AC, Weissman TA, Dammerman RS, Kriegstein AR (2001) Neurons derived from radial glial cells establish radial units in neocortex. Nature 409:714-720.

Owens DF, Kriegstein AR (2002) Is there more to GABA than synaptic inhibition? Nat Rev Neurosci 3:715-727.

Owens DF, Boyce LH, Davis MB, Kriegstein AR (1996) Excitatory GABA responses in embryonic and neonatal cortical slices demonstrated by gramicidin perforated-patch recordings and calcium imaging. J Neurosci 16:6414-6423.

Owens DF, Liu X, Kriegstein AR (1999) Changing properties of GABA(A) receptor-mediated signaling during early neocortical development. J Neurophysiol 82:570-583.

Plotkin MD, Snyder EY, Hebert SC, Delpire E (1997) Expression of the $\mathrm{Na}-\mathrm{K}-2 \mathrm{Cl}$ cotransporter is developmentally regulated in postnatal rat brains: a possible mechanism underlying GABA's excitatory role in immature brain. J Neurobiol 33:781-795.

Rajan I, Cline HT (1998) Glutamate receptor activity is required for normal development of tectal cell dendrites in vivo. J Neurosci 18:7836-7846.

Rivera C, Voipio J, Payne JA, Ruusuvuori E, Lahtinen H, Lamsa K, Pirvola U, Saarma M, Kaila K (1999) The K+/Cl- co-transporter KCC2 renders GABA hyperpolarizing during neuronal maturation. Nature 397:251-255.
Saito T, Nakatsuji N (2001) Efficient gene transfer into the embryonic mouse brain using in vivo electroporation. Dev Biol 240:237-246.

Scheetz AJ, Nairn AC, Constantine-Paton M (1997) N-methyl-D-aspartate receptor activation and visual activity induce elongation factor-2 phosphorylation in amphibian tecta: a role for N-methyl-D-aspartate receptors in controlling protein synthesis. Proc Natl Acad Sci USA 94:14770-14775.

Shi SH, Hayashi Y, Petralia RS, Zaman SH, Wenthold RJ, Svoboda K, Malinow R (1999) Rapid spine delivery and redistribution of AMPA receptors after synaptic NMDA receptor activation. Science 284:1811-1816.

Sin WC, Haas K, Ruthazer ES, Cline HT (2002) Dendrite growth increased by visual activity requires NMDA receptor and Rho GTPases. Nature 419:475-480.

Tao HW, Poo MM (2005) Activity-dependent matching of excitatory and inhibitory inputs during refinement of visual receptive fields. Neuron 45:829-836.

Tyzio R, Represa A, Jorquera I, Ben-Ari Y, Gozlan H, Aniksztejn L (1999) The establishment of GABAergic and glutamatergic synapses on CA1 pyramidal neurons is sequential and correlates with the development of the apical dendrite. J Neurosci 19:10372-10382.

Wollmuth LP, Kuner T, Sakmann B (1998a) Adjacent asparagines in the NR2-subunit of the NMDA receptor channel control the voltagedependent block by extracellular Mg2+. J Physiol (Lond) 506:13-32.

Wollmuth LP, Kuner T, Sakmann B (1998b) Intracellular Mg2+ interacts with structural determinants of the narrow constriction contributed by the NR1-subunit in the NMDA receptor channel. J Physiol (Lond) 506:33-52.

Wu G, Malinow R, Cline HT (1996) Maturation of a central glutamatergic synapse. Science 274:972-976.

Wu GY, Cline HT (1998) Stabilization of dendritic arbor structure in vivo by CaMKII. Science 279:222-226.

Xiao MY, Wasling P, Hanse E, Gustafsson B (2004) Creation of AMPAsilent synapses in the neonatal hippocampus. Nat Neurosci 7:236-243.

Zhou Q, Homma KJ, Poo MM (2004) Shrinkage of dendritic spines associated with long-term depression of hippocampal synapses. Neuron 44: 749-757. 